\title{
Determinants of infant feeding practices among Black mothers living with HIV: a multinomial logistic regression analysis
}

\author{
Josephine Etowa', Jean Hannan², Egbe B. Etowa ${ }^{3^{*}}$ D, Seye Babatunde ${ }^{4}$ and J. Craig Phillips ${ }^{1}$
}

\begin{abstract}
Background: Infant feeding practices are imperative for babies' and mothers' health and emotional wellbeing. Although infant feeding may seem simple, the decisions surrounding it are complex and have far-reaching implications for women globally. This is an especially difficult concern among mothers living with HIV because breastfeeding can transmit HIV from mother to child. This is further complicated by cultural expectations in case of Black mothers living with HIV. This paper discusses determinants of infant feeding practices among Black mothers living with HIV who were on anti-retroviral therapy (ART) in two North American cites and one African city.

Methods: A cross-sectional, multi-country survey using venue-based convenience sampling of Black mothers living with HIV was employed. The effective response rates were 89\% $(n=89)$ in Ottawa, Canada; 67\% $(n=201)$ in Miami, Florida, US; and 100\% $(n=400)$ in Port Harcourt, Nigeria, equaling a total sample size of 690. Data were collected in Qualtrics and managed in Excel and SPSS. Multinomial logistic regression analyses were used to determine the factors influencing the mothers' infant feeding practices (Exclusive Formula Feeding $[E F F]=1$; Mixed Feeding $[M F]=2$; and Exclusive Breastfeeding [EBF while on ART] =3).
\end{abstract}

Results: The results highlight socio-demographics, EFF determinants, and EBF determinants. The statistically significant determinants of infant feeding practices included national guideline on infant feeding, cultural beliefs and practices, healthcare systems, healthcare personnel, infant feeding attitudes, social support, and perceived stress. Mothers' mean ages were Ottawa (36.6 \pm 6.4$)$, Miami (32.4 \pm 5.8$)$, and Port Harcourt (34.7 \pm 5.7$)$. All sampled women gave birth to least one infant after their HIV diagnoses. Statistically significant $(p<.05)$ determinants of EFF relative to MF were the national guideline of EFF (relative risk $[R R]=218.19)$, cultural beliefs $(R R=.15)$, received healthcare $(R R=21.17)$, received healthcare through a nurse/midwife $(R R=3.1)$, and perceived stress $(R R=.9)$. Statistically significant determinants of EBF relative to MF were received healthcare $(R R=20.26)$, received healthcare through a nurse/midwife $(R R=2.31)$, functional social support $(R R=1.07)$, and perceived stress $(R R=.9)$.

(Continued on next page)

\footnotetext{
* Correspondence: eetowa@uwindsor.ca

${ }^{3}$ Department of Sociology, Anthropology \& Criminology; Faculty of Arts,

Humanities \& Social Sciences, 401 Sunset Avenue, Windsor, Ontario N9B 3P4,

Canada

Full list of author information is available at the end of the article
}

(C) The Author(s). 2021 Open Access This article is licensed under a Creative Commons Attribution 4.0 International License, which permits use, sharing, adaptation, distribution and reproduction in any medium or format, as long as you give appropriate credit to the original author(s) and the source, provide a link to the Creative Commons licence, and indicate if changes were made. The images or other third party material in this article are included in the article's Creative Commons licence, unless indicated otherwise in a credit line to the material. If material is not included in the article's Creative Commons licence and your intended use is not permitted by statutory regulation or exceeds the permitted use, you will need to obtain permission directly from the copyright holder. To view a copy of this licence, visit http://creativecommons.org/licenses/by/4.0/ The Creative Commons Public Domain Dedication waiver (http://creativecommons.org/publicdomain/zero/1.0/) applies to the data made available in this article, unless otherwise stated in a credit line to the data. 
(Continued from previous page)

Conclusion: While cultural beliefs and perceived stress favoured MF over EFF, advice of healthcare workers, and the care received from a nurse/midwife improved EFF over MF. Also while the mothers' perceived stress favoured MF over EBF, advice of their nurses or midwife and the social support improved EBF over MF. The providers advice was congruent with WHO and national guidelines for infant feeding among mothers living with HIV. These results have implications for nursing, healthcare practice, and policies on infant feeding practices for mothers living with HIV.

Keywords: Infant feeding, HIV, Black mothers, Sociocultural and psychosocial determinants, Healthcare

\section{Background}

Infant feeding practices are imperative for babies' and mothers' health and emotional wellbeing. Although infant feeding may seem simple, the decisions surrounding it are complex and have far-reaching implications for women globally. This is especially difficult for mothers living with HIV because breastfeeding can transmit HIV from mother to child [1]. Thus, eliminating mother to child transmission (MTCT) of HIV is a global health priority in the fight against HIV and in breaking the vicious cycle of HIV transmission to newborns [2-4].

In 2010, the World Health Organization (WHO) recommended that mothers living with HIV adopt Exclusive Breastfeeding (EBF) for up to 6 months and continue breastfeeding until the infant was 12 months old, provided that they and/or the infants were taking antiretroviral therapy (ART) during the same period [5]. The 2016 update to this recommendation states that, as long as the mother is on lifelong ART, she can continue breastfeeding for up to 24 months or longer until a nutritionally adequate and safe diet without breast milk can be provided [6]. However, the 2016 update did not replace the 2010 guidelines, and mothers living with $\mathrm{HIV}$ are recommended to avoid breastfeeding if formula feeding is accessible, feasible, affordable, sustainable, and safe. Consequently, the implementation of these guidelines varies globally [4]. High income countries, such as Canada and the United States (US) recommend EFF, while low- to middle-income countries, such as Nigeria, recommend EBF while on ART [7]. Although being on ART and monitoring viral are a critical factor, some mothers in Nigeria reported that they would still breastfeed their children, irrespective of their HIV status [8]. In southwestern Nigeria, breastfeeding is perceived as essential to a baby's health - strengthening the physical and spiritual bonds between mothers and children [9]. In contrast, women in Canada and the US risk prosecution when potentially transmitting HIV to infants through breastfeeding [10]. Even with a less than 2\% aggregated population risk of vertical transmission when the mother is on ART [11], the potential for prosecution remains in both countries [12].

HIV remains an important public health concern in Canada and the US, where achievements in reducing the
MTCT of HIV, which is an intense stress factor for many women living with HIV, has arisen from offering HIV testing and providing ART to pregnant women [13]. Aside from the tension emanating from the differing guideline implementation between countries of residence and origin, immigrant Black women, especially those living in high income countries, face a more intense dilemma of either yielding to existing cultural norms on mothering [5] or adhering to public health policy on infant feeding. Culture influences the desire for a particular style of mothering, whether the mother is living with HIV or not [14]. Hence, infant feeding practices among mothers living with HIV must be understood via their sociocultural contexts, with due consideration given to the mothers' mental health conditions accentuated by HIV.

Studies among African immigrant women have shown that they upheld their cultural beliefs about infant feeding upon moving to Canada and that the desire to breastfeed was a common existential perception shared by African women, including those living with HIV [1517]. At onset of immigration to the North America, Black mothers bring in the culture of breastfeeding and are more likely to breastfeed, but with time Formula feeding acculturation sets in [18, 19], especially with changes in socioeconomic status and occupational demands. In the 1970s at the boom of formula industries, many Black mothers would have already imbibed the culture of formula feeding before migration to North America, and until recently a few well-educated and in the working class would hold the culture of formula feeding prior to migration $[18,20]$. In contrast, among American born Black mothers breastfeeding culture is more common among women who are older, married, and possess high levels of education, even though breastfeeding rates is generally lower in African American mothers than other ethnic groups in the US [21]. Hence cultural variations in infant feeding practices may exists between migrants versus non-migrant Black mothers, and between Black mothers of different socioeconomic status.

A study of Black mothers in Canada documented that adherence to the national guidelines of adopting EFF while living with HIV was associated with difficulty in 
maintaining their ascribed social roles as respected wives, mothers, and members of society [3]. Additionally, the fear of alienation and stigmatization often makes it difficult for women to decide not to breastfeed [22]. This tension associated with adherence to national guidelines and meeting cultural expectations is a source of significant stress for mothers, who feel pressure from both society and themselves [23, 24]. Health providers in a US study reported non-adherence to EFF by their HIV+ patients due to the stigma associated with not breastfeeding [25]. Thus, Black women living with HIV in Canada and the US may be caught between conflicting cultural expectations, public policies, and legal obligations related to infant feeding. However, no studies have specifically examined the infant feeding practices and the sociocultural context of motherhood among Black women, especially those living with HIV in high income countries.

Although this paper primarily presents quantitative results, this has been drawn from a broader mixedmethods study, which sought to understand the experiences of Black mothers residing in two cities in two high income countries (Ottawa, Canada, and Miami, Florida, US) vis a vis those of indigenous Black women in Port Harcourt, Nigeria [26]. This paper has identified the determinants of infant feeding practices among Black mothers living with HIV in the two North American cities compared to those in the African city of Port Harcourt. Black mothers in this context were African, Caribbean, and Black (ACB) mothers residing in Ottawa, Canada; Miami-Florida, USA; or Port Harcourt, Nigeria. It includes women of African descent who were either born in these cities or those who migrated into those cities from elsewhere. Analysis of the different infant feeding practices of the Black mothers living with HIV in these three sites may inform health care education, practice, and policy.

\section{Methods}

This research employed a cross-sectional, multi-country survey using venue-based convenience sampling of Black mothers living with HIV. Venue-based sampling was employed because probability sampling was highly inefficient due to several factors including the relatively small size of ACB population in both Ottawa, Canada and Miami, US. In Canada ACB people make up only $3.5 \%$ of the Canada's total population [27], and this in part explain the small sample size of Ottawa site. Moreover, persons living with HIV are a hard to reach population, and reaching Black women proved to be even harder among people living with HIV who had a baby after HIV diagnosis. Only Black women who had babies since 2010 when the first WHO infant feeding guidelines were developed were recruited. The implementation of WHO guideline in 2010 marked a global milestone in HIV care for this population. The sensitivity of the topic, including fear of selfdisclosing HIV status and stigma were also obstacles to recruitment by probability sampling. Sampling were done at all identified event venues of the mothers to reduce sampling error. The venues were identified community resource centers, public health facilities and AIDS service organizations where people living with HIV will normally meet or receive health care. Honorarium were given to participants in the study. Trained research assistants, graduate students and project staff recruited participants from the identified venues between 2016 and 2018. Data collection was initiated in 2016 and it continued until 2018 because of the difficulty of reaching participants in a shorter period. Data collection instruments included paper or electronic (online or offline) survey questionnaire using a computer tablet, depending on participants' preference. For confidentiality and anonymity, all participant data were coded using study-generated identification entered in Qualtrics ${ }^{\mathrm{XM}}[28]$. The data were later downloaded and managed in Excel and SPSS files.

We estimated a minimum sample sizes of 800 from all three sites. This was large enough to detect small to moderate effects observed between variables in quantitative analysis assuming an alpha of .05 and power of .8 . Hence based on the relative frequencies of Black, HIVpositive women of child-bearing age making an infant feeding choice at desired precision level of $5 \%$, estimated sample size in each site were: Ottawa $(n=100)$; Port Harcourt $(n=400)$; and Miami $(n=300)$. The effective response rates were: $89 \%(n=89)$ in Ottawa, $67 \%(n=$ $201)$ in Miami, and $100 \%(n=400)$ in Port Harcourt, giving a total sample size of 690 . The effective response rates were determined by the ratio of surveys questionnaire completed to the total number of survey questionnaire issued per site multiplied by 100 . The inclusion criteria were as follows: being an African, a Caribbean, or Black mother who migrated or was born in Canada; living with HIV; and having given birth to at least one child after HIV diagnosis. Almost all the mothers were on ART. All participants were between 18 and 49 years of age and resided in one of the three study sites. Participants completed questionnaires to provide demographic information, infant feeding practices, sociocultural characteristics, prenatal information, and healthcare information. They also completed instruments assessing their psychosocial attributes, including functional social support, infant feeding attitudes and perceived stress.

The Functional Social support scale was used, and this has been described in a previous study [29]. It is a 7items scale adapted from the Duke-UNC Functional Social Support Questionnaire [30], Cohen perceived stress scale and Iowa Infant Feeding Attitude Scales were used as described in previous work, Infant feeding attitudes 
was measured using the 17 -item validated Iowa Infant Feeding Attitude Scale (IIFAS) [31]. A maximum score of 85 was attainable on the scale with high score showing positive attitude towards breastfeeding. Stress was rated based on 10-Items Cohen Perceived Stress Scale $[32,33]$. The Scale (PSS) scale is validated and have been used among diverse populations including among mothers living with HIV. A total score of 40 was attainable on the scale. Higher scores show higher levels of stress.

Multinomial logistic regression analyses were used to estimate determinants of the mothers' infant feeding practices. These were conducted in five consecutive levels of SPSS analyses, designated as Models 1 to 5 (Tables 5 and 6). Each block of selected determinants, added to the consecutive model at each level of analysis significantly improved the models' fits, and the final level, Model 5, was chosen to explain the relationship. Sociodemographic variables (e.g., age, education) were controlled for in this model. The levels of statistical significance were set at an alpha criterion of $p<.05$. Infant feeding practices, the outcome (dependent) variable in these analyses was categorical with three outcome levels $(\mathrm{EFF}=1, \mathrm{MF}=2$ and $\mathrm{EBF}=3)$. MF was used as the reference category because it signified non-adherence to infant feeding guidelines in all national contexts. Blocks of predictor (independent) variables were selected based on pre-defined factors in research protocols informed by a systematic review preceding this work [26]. Explicit conceptual framework on variables selection is provided in the research protocol [34]. Details of these blocks of independent variables were entered into each of the successive multinomial logistic regression models, and their measurements are described below.

In Model 1, "national policy guideline" was the only included variable. It was dichotomized as guideline of $\mathrm{EFF}=1$, and guideline of EBF while on $\mathrm{ART}=0 . \mathrm{Na}$ tional guideline on infant feeding, a priori, was expected to be a major determinant of infant feeding practices. Therefore, it was included alone in Model 1 to study and separate its unique effect before inclusion of other variables in subsequent models. In Model 2, sociodemographic variables were entered: mother's age in years, marital status (married $=1$, not married $=0$ ), number of children born after HIV diagnosis, number of years of formal education, and type of employment (salaried or waged employment $=1$, otherwise $=0$ ). This block of variables have statistically significant $(p<.05)$ contributory effect on Model 2, justifying its inclusion in subsequent models. In Model 3, sociocultural factors were included. The sociocultural factors were spouse or baby's father's influence, family influence, cultural beliefs, healthcare, healthcare workers. To measure these sociocultural factors, we transformed their respective scoring on the Influence of Specific Referent Scale (ISR) [35] to binary variables. For example, mothers were asked: "How important is your baby's father's opinion to you about how to feed your baby?" The ISR Scale options of "very unimportant," "unimportant," "unsure," "important" and "very important" were coded as 1 for a response of "important" or "very important" (proxy = important) and 0 for all other values (proxy = unimportant). In Model 4, healthcare-related variables were entered. Mothers were asked: "Did you receive healthcare during the period you were pregnant and living with HIV?". If the response was "yes," the answer was coded as 1, and "no" was coded as 0 . Mothers were then asked from whom they received prenatal care. A response of "nurse/midwife" was coded as 1 , and a response of "medical doctor/clinical officer" was coded as 0 . Responses to other categories for this question on sources of prenatal care included "service providers" $(n=2)$, "I choose not to answer" $(n=8)$ and "missing values" $(n=9)$. All these were excluded by listwise deletion from the analyses. Deleted observations were not uniquely different from undeleted observations and account for $11.3 \%(n=85)$ of the total sample size $(N=$ 690). The final model, Model 5, incorporated variables from previously validated psychosocial instruments expected to influence infant feeding practices. Functional social support, Cohen's Perceived Stress Scale (PSS), and the Iowa Infant Feeding Attitude Scale (IIFAS) were entered as continuous variables, in addition to the previous determinants already in the model.

\section{Results}

This section presents three subsections of the findings: 1) sociodemographic characteristics of the study population; 2) determinants of EFF relative to MF; and 3) determinants of EBF relative to MF

\section{Sociodemographic characteristics of the study population} A preliminary description of sociodemographic variables was necessary because their distribution is a well-known potential source of variability among many outcome variables, including variations in infant feeding practices in mothers living with HIV [36-38]. Hence, Table 1 summarizes the key demographic characteristics of the ACB mothers living with HIV.

Average age of the mothers was 34 years, however, the largest percentage of them were aged 35-44 years in Ottawa $(n=37,54.4 \%)$. In Port Harcourt, almost equal majority of the women were aged 25-34 years $(n=180$, $45.0 \%)$ and $3-44$ years $(n=184,46.0 \%)$. The largest percentage of the women were aged 25 to 34 years in Miami $(n=91,50.3 \%)$. Most mothers were either single, separated, divorced or widowed in Ottawa $(n=57,66.3 \%)$ and the greater percentage were married in Port 
Table 1 Socioeconomic characteristics of the mothers

\begin{tabular}{|c|c|c|c|c|}
\hline Socioeconomic characteristics & Ottawa, Canada n (\%) & $\begin{array}{l}\text { Port Harcourt, } \\
\text { Nigeria n (\%) }\end{array}$ & Miami-Florida, USA n (\%) & $\begin{array}{l}\text { All Sites } \\
\text { n (\%) }\end{array}$ \\
\hline \multicolumn{5}{|l|}{ Mothers' age (categories) } \\
\hline $18-24$ years & $2(2.9)$ & $18(4.5)$ & $15(8.3)$ & $35(5.4))$ \\
\hline $25-34$ years & $20(29.4)$ & $180(45.0)$ & $91(50.3)$ & $291(44.8)$ \\
\hline $35-44$ years & $37(54.4)$ & $184(46.0)$ & $74(40.9)$ & $295(45.5)$ \\
\hline $45-49$ years & $9(13.2)$ & $18(4.5)$ & $1(0.5)$ & $28(4.3)$ \\
\hline Total valid responses & $68(100)$ & $400(100)$ & $181(100)$ & $649(100)$ \\
\hline \multicolumn{5}{|l|}{ Relationship status: } \\
\hline Single/separated/divorced/widowed & $57(66.3)$ & $57(14.4)$ & $61(33.5)$ & $175(26.3)$ \\
\hline Married & $29(33.7)$ & $340(85.6)$ & $121(66.5)$ & $490(73.7)$ \\
\hline Total valid responses & $86(100)$ & $397(100)$ & $182(100)$ & $665(100)$ \\
\hline \multicolumn{5}{|l|}{ Number of persons in household } \\
\hline$<5$ persons & $56(66.7)$ & $222(56.1)$ & $125(77.2)$ & $403(62.8)$ \\
\hline$\geq 5$ persons & $28(33.3)$ & $174(43.9)$ & $37(22.8)$ & $239(37.2)$ \\
\hline Total valid responses & $84(100)$ & $396(100)$ & $162(100)$ & $642(100)$ \\
\hline \multicolumn{5}{|l|}{ Number of children born after HIV+ } \\
\hline$<3$ children & $43(87.8)$ & $372(93.0)$ & $193(96.0)$ & $608(93.5)$ \\
\hline$\geq 3$ children & $6(12.2)$ & $28(7.0)$ & $8(4.0)$ & $42(6.5)$ \\
\hline Total valid responses & $49(100)$ & $400(100)$ & $201(100)$ & $650(100)$ \\
\hline \multicolumn{5}{|l|}{ Number of years since HIV+ } \\
\hline $1-5$ years & $9(12.2)$ & $178(45.2)$ & $29(24.4)$ & $216(36.8))$ \\
\hline $6-10$ years & $24(32.4)$ & $166(42.1)$ & $28(23.5)$ & $218(37.1)$ \\
\hline$>10$ years & $41(55.4)$ & $50(12.7)$ & $62(52.1)$ & $153(26.1)$ \\
\hline Total valid responses & $74(100)$ & $394(100)$ & $119(100)$ & $587(100)$ \\
\hline \multicolumn{5}{|l|}{ On HIV treatment (ART)? } \\
\hline Yes & $50(96.2)$ & $399(99.8)$ & $187(97.4)$ & $636(98.8)$ \\
\hline No & $0(0.0)$ & $1(0.2)$ & $0(0.0)$ & $1(0.1)$ \\
\hline I choose not to answer & $2(3.8)$ & $0(0.0)$ & $5(2.6)$ & $7(1.1)$ \\
\hline Total valid responses & $52(100)$ & $400(100)$ & $192(100)$ & $644(100)$ \\
\hline \multicolumn{5}{|l|}{ Education: } \\
\hline Primary school & $1(1.2)$ & $42(10.7)$ & $0(0.0)$ & $43(6.4)$ \\
\hline High school, technical or vocational school & $34(40.0)$ & $250(63.4)$ & $131(66.5)$ & $415(61.4)$ \\
\hline College or university & $50(58.8)$ & $102(25.9)$ & $66(33.5)$ & $218(32.2)$ \\
\hline Total valid responses & $85(100)$ & $394(100)$ & $187(100)$ & $676(100)$ \\
\hline \multicolumn{5}{|l|}{ Employment status: } \\
\hline Employed (full time or part time) & $51(57.3)$ & $320(87.9)$ & $65(32.7)$ & $436(66.9)$ \\
\hline Unemployed & $38(42.7)$ & $44(12.1)$ & $134(67.3)$ & $216(33.1)$ \\
\hline Total valid responses & $89(100)$ & $364(100)$ & $189(100)$ & $652(100)$ \\
\hline \multicolumn{5}{|l|}{ Main source of income: } \\
\hline Wages or salaries & $40(48.8)$ & $66(20.1)$ & $64(40.3)$ & $170(29.9)$ \\
\hline Self employment income & $5(6.1)$ & $260(79.3)$ & $8(5.0)$ & $273(48.0)$ \\
\hline Social assistance & $20(24.4)$ & $0(0.0)$ & $77(48.4)$ & $97(17.0)$ \\
\hline Other income sources & $17(20.7)$ & $2(0.6)$ & $10(6.3)$ & $29(5.1)$ \\
\hline Total valid responses & 82 (100) & $328(100)$ & 159 (100) & 569 (100) \\
\hline
\end{tabular}


Harcourt ( $n=340,85.6 \%)$ and in Miami $(n=121,66.5 \%)$. Household sizes were mostly small (less than 5 persons) in Ottawa $(n=55,66.7 \%)$, Port Harcourt $(n=222$, $56.1 \%)$ and Miami ( $n=125,77.2 \%)$. All mothers had at least a baby after being diagnosed of HIV, and almost all gave birth to only one or two children since living with HIV in Ottawa $(n=43,87.8 \%)$, Port Harcourt $(n=372$, 93.0\%), and Miami ( $n=193,96.0 \%)$. The average number of years since HIV diagnosis was 8.1 years with the majority diagnosed for HIV since more than 10 years ago in Ottawa $(n=41,55.4 \%)$, and Miami $(n=62,52.1 \%)$. Most mothers in Port Harcourt were either diagnosed in the past 5 years $(n=178,45.2 \%)$ or 6 to 10 years $(n=166$, 42.1\%) prior to the survey. Almost all mothers were on ART in Ottawa $(n=50,96.2 \%)$, Port Harcourt $(n=399$, 99.8\%) and Miami ( $n=187,97.4 \%)$. Most of the mothers in Port Harcourt had completed high school, technical or vocational education $(n=415,61.4 \%)$, or completed a college or a university education $(n=218,32.2 \%)$. Miami had largest percentage $(n=131,66.5 \%)$ of mothers who completed high school, technical or vocational education while $33.5 \%(n=66)$ or completed a college or a university education $(n=66,33.5 \%)$. In Port Harcourt, $63.4 \%$ $(n=210)$ completed high school, technical or vocational education while $25.9 \%(n=103)$ finished a college or a university education. Mothers reported a wide range of employment (full- or part-time), with the highest rate in Port Harcourt $(n=320,87.9 \%)$ and the lowest in Miami $(n=65,32.7 \%)$.

Table 2 provides descriptive statistics for the mothers' infant feeding practices. It also describes each mother's perception of her social network's opinions about appropriate infant feeding methods. Most Black mothers living with HIV practiced EFF in Ottawa $(n=79,90.8 \%)$ and Miami $(n=146,75.7 \%)$. In contrast, only $57(18.1 \%)$ mothers in Port Harcourt practiced EFF; most of them $(n=210,66.7 \%)$ practiced EBF by following their national guidelines.

Most of the mothers in Ottawa $(n=56,65.1 \%)$ and Miami ( $n=106,53.0 \%)$ perceived that their spouses, partners or baby's fathers supported EFF. In Ottawa, most ( $n=57,67.1 \%)$ other family members (grandparents, siblings, in-laws, etc.) supported EBF, while the majority $(n=114,56.7 \%)$ supported EFF in Miami. In Port Harcourt, most $(n=213,66.8 \%)$ of the women reported that their spouses, partners or baby's fathers supported EBF. Proportions of the mothers in Port Harcourt who reported other relatives' opinions about infant feeding practices included EFF $(n=35,12.1 \%) ; \operatorname{MF}(n=86$, $29.7 \%)$ and EBF $(n=114,39.3 \%)$. In Port Harcourt, 55 mothers $(19.0 \%)$ chose not to answer to the question of other relatives' opinion on their infant feeding practices. Most mothers in Ottawa $(n=78,89.7 \%)$ and Miami $(n=$ $162,80.6 \%)$ perceived that their health providers supported EFF, and, in Port Harcourt ( $n=269,84.3 \%)$, most of them believed their health providers promoted EBF. Mothers had divergent views about whether their cultural beliefs or practices inhibited infant feeding practices. In Ottawa, 18 mothers $(22.5 \%)$ reported that their culture of origin prohibited EFF; seven (8.8\%) believed their culture disallowed MF; 29 (36.3\%) explained that their culture forbade EBF; and 26 (32.5\%) chose not to answer. Similarly, in Miami, 27 mothers (14.0\%) reported that their culture of origin culture prohibited EFF; 13 (6.7\%) believed their culture disallowed MF; 59 (30.6\%) stated that their culture forbade EBF; and 94 (48.7\%) chose not to answer. In Port Harcourt, responses to this question about the influence of culture were sparse, with only 63 valid responses out of 400 respondents. The greater percent of the mothers did not answer this question. Based on the valid responses, eight mothers $(12.7 \%)$ reported that their culture of origin prohibited EFF, four (6.3\%) viewed their culture as disallowing MF, 12 (19.0\%) believed their culture forbade EBF; and 39 (61.9\%) chose not to answer.

Table 3 describes statistics of other sociocultural variables, some of which were included in the analysis model. These variables included healthcare information during pregnancy while living with HIV, mothers' ratings of their spouses, and other family members' opinions about infant feeding practices, mothers' ratings of health providers' views about infant feeding options, and mothers' ratings of how cultural beliefs and practices influence their methods of feeding their babies. Concerning healthcare information, the mothers were asked if they received health care during pregnancy while living with HIV, they were also asked to name the category of health care staff that rendered the health care services. Almost all mothers from all sites $(n=659,96.6 \%)$ received health care during their pregnancy while living with HIV. In Ottawa $(n=85,96.6 \%)$, Miami $(n=179$, 91.3\%) and Port Harcourt $(n=395,99.2 \%)$ - received healthcare from healthcare personnel when they were pregnant while living with HIV. A larger percentage of the mothers received the health care from medical doctor or a clinical officer in Ottawa $(n=47,55.3 \%)$ and in Miami $(n=151,84.4)$. In contrast, most of the mothers in in Port Harcourt $(n=305,77.2 \%)$ received health care from a nurse.

Most mothers in all sites $(n=480,70.2 \%)$ rated the opinions of their spouses/partners/babies' fathers about infant feeding as being "important" or "very important." At individual site levels, this rating was broken down into Ottawa $(n=62,71.3 \%)$, Miami $(n=108,53.7 \%)$ and Port Harcourt $(n=310,78.3 \%)$. Most mothers reported that they either "cared" or "cared very much" about other family members' (grandmothers, mothers-in-law, siblings, etc.) opinions about infant feeding practices in 
Table 2 Sociocultural variables related to infant feeding practices of the Black mothers living with HIV

\begin{tabular}{|c|c|c|c|c|}
\hline Indicator & Ottawa, Canada n (\%) & Port Harcourt, Nigeria n (\%) & Miami-Florida, USA n (\%) & All Sites $\mathrm{n}(\%)$ \\
\hline \multicolumn{5}{|c|}{ When it comes to feeding your baby, do you practice exclusive formula feeding? } \\
\hline Yes, exclusive formula feeding & $79(90.8)$ & $57(18.1)$ & $146(75.6)$ & $282(47.4)$ \\
\hline No, mixed feeding & $3(3.4)$ & $48(15.2)$ & $14(7.3)$ & $65(10.9)$ \\
\hline No, exclusive breastfeeding & $5(5.8)$ & $210(66.7)$ & $10(5.2)$ & $225(37.8)$ \\
\hline I choose not to answer & $0(0.0)$ & $0(0.0)$ & $23(11.9)$ & $23(3.9)$ \\
\hline Total valid responses & $87(100)$ & $315(100)$ & $193(100)$ & $595(100)$ \\
\hline \multicolumn{5}{|c|}{ Your spouse/partner/baby's father thinks you should practice? } \\
\hline Exclusive formula feeding & $56(65.1)$ & $57(17.9)$ & $106(53.0)$ & $219(36.2)$ \\
\hline Mix feed & $4(4.7)$ & $49(15.3)$ & $10(5.0)$ & $63(10.4)$ \\
\hline Exclusive breastfeeding & $10(11.6)$ & $213(66.8)$ & $20(10.0)$ & $243(40.2)$ \\
\hline I choose not to answer & $16(18.6)$ & $0(0.0)$ & $64(32.0)$ & $80(13.2)$ \\
\hline Total valid responses & $86(100)$ & $319(100)$ & $200(100)$ & $605(100)$ \\
\hline \multicolumn{5}{|c|}{ Your other family members or close relatives thinks you should practice? } \\
\hline Exclusive formula feeding & $13(15.3)$ & $35(12.0)$ & $114(56.7)$ & $162(28.1)$ \\
\hline Mix feed & $7(8.2)$ & $86(29.7)$ & $14(7.0)$ & $107(18.6)$ \\
\hline Exclusive breastfeeding & $57(67.1)$ & $114(39.3)$ & $25(12.4)$ & $196(34.0)$ \\
\hline I choose not to answer & $8(9.4)$ & $55(19.0)$ & $48(23.9)$ & $111(19.3)$ \\
\hline Total valid responses & $85(100)$ & $290(100)$ & $201(100)$ & $576(100)$ \\
\hline \multicolumn{5}{|c|}{ What type infant feeding do your healthcare provider think you should practice? } \\
\hline Exclusive formula feeding & $78(89.7)$ & $37(11.9)$ & $162(80.6)$ & $277(46.3)$ \\
\hline Mix feed & $4(4.6$ & $2(0.6)$ & $6(3.0)$ & $12(2.0)$ \\
\hline Exclusive breastfeeding & $4(4.6)$ & $269(86.7)$ & $14(7.0)$ & $287(48.0)$ \\
\hline I choose not to answer & $1(1.1)$ & $2(0.6)$ & $19(9.4)$ & $22(3.7)$ \\
\hline Total valid responses & $87(100)$ & $310(100)$ & $201(100)$ & $598(100)$ \\
\hline \multicolumn{5}{|c|}{ Are there cultural beliefs and practices in your place of origin about methods of feeding your baby? } \\
\hline Yes & $59(67.8)$ & $26(6.6)$ & $62(30.8)$ & $147(21.5)$ \\
\hline No & 17 (19.6) & $367(92.9)$ & $88(43.8)$ & $472(69.1)$ \\
\hline I choose not to answer & $11(12.6)$ & $2(0.5)$ & $51(25.4)$ & $64(9.4)$ \\
\hline Total valid responses & $87(100)$ & $395(100)$ & $201(100)$ & $683(100)$ \\
\hline \multicolumn{5}{|c|}{ Does the cultural beliefs oppose any of the infant feeding methods? } \\
\hline Yes, exclusive breast feeding & $18(22.5)$ & $8(12.7)$ & $27(14.0)$ & $53(15.8)$ \\
\hline Yes, mix feeding & $7(8.8)$ & $4(6.4)$ & $13(6.7)$ & $24(7.1)$ \\
\hline Yes, exclusive formula feeding & $29(36.2)$ & $12(19.0)$ & $59(30.6)$ & $100(29.8)$ \\
\hline I choose not to answer & $26(32.5)$ & $39(61.9)$ & $94(48.7)$ & $159(47.3)$ \\
\hline Total valid responses & $80(100)$ & $63(100)$ & $193(100)$ & $336(100)$ \\
\hline
\end{tabular}

Ottawa $(n=66,74.1 \%)$ and Miami $(n=97,48.3 \%)$. In Port Harcourt, however, the majority $(n=194,53.6 \%)$ did not care at all, did not care or were unsure about their other family members' opinions on infant feeding methods. Mothers rated healthcare providers exceptionally highly, as all women in Ottawa $(n=89,100 \%)$ either "cared" or "cared very much" about their healthcare providers' recommendations. Also, almost all mothers in Port Harcourt $(n=393,98.5 \%)$ and Miami $(n=170$, $84.6 \%)$ either "cared" or "cared very much" about their healthcare providers' infant feeding recommendations. When asked how their cultural beliefs and practices influenced their infant feeding practices, most mothers in all three sites $(n=497,78.5 \%)$ reported either "not at all, " "not much" or "unsure." Site specific breakdown show that about half of the mothers who provided valid responses in Ottawa $(n=43,49.4 \%)$ and Miami $(n=60$, $46.1 \%)$ rated the influence of cultural beliefs and practices on their infant feeding practices as "not at all," "not much," or "unsure." In Port Harcourt, the vast majority 
Table 3 Other sociocultural factors that potentially influence infant feeding practices

\begin{tabular}{|c|c|c|c|c|}
\hline Indicator & Ottawa, Canada n (\%) & Port Harcourt, Nigeria n (\%) & Miami-Florida, USA n (\%) & $\begin{array}{l}\text { All Sites } \\
\text { n (\%) }\end{array}$ \\
\hline \multicolumn{5}{|l|}{ Did you receive health care during pregnancy? } \\
\hline Yes & 85 (96.6) & $395(99.2)$ & $179(91.3)$ & $659(96.6)$ \\
\hline No & $3(3.4)$ & $3(0.8)$ & $17(8.7)$ & $23(3.4)$ \\
\hline Total valid responses & $88(100)$ & $398(100)$ & $196(100)$ & $684(100)$ \\
\hline \multicolumn{5}{|c|}{ From whom did you receive health care during pregnancy? } \\
\hline Medical doctor, clinical officer & $47(55.3)$ & $88(22.3)$ & $151(84.4)$ & $286(43.4)$ \\
\hline Nurse, Midwife & $6(7.1)$ & $305(77.2)$ & $7(3.9)$ & $318(48.2)$ \\
\hline Other sources & $32(37.6)$ & $2(0.5)$ & $21(11.7)$ & $55(9.4)$ \\
\hline Total valid responses & $85(100)$ & $395(100)$ & $179(100)$ & $659(100)$ \\
\hline \multicolumn{5}{|c|}{ How important is your spouse/partner/baby's father's opinion to you about how to feed your baby? } \\
\hline Very unimportant, unimportant, unsure & $20(23.0)$ & $72(18.8)$ & $65(32.3)$ & $157(23.0)$ \\
\hline Important, very important & $62(71.3)$ & $310(78.3)$ & $108(53.7)$ & $480(70.2)$ \\
\hline I choose not to answer & $5(5.7)$ & $14(3.5)$ & $28(14.0)$ & $47(6.8)$ \\
\hline Total valid responses & $87(100)$ & $396(100)$ & $201(100)$ & $684(100)$ \\
\hline \multicolumn{5}{|c|}{ How much do you care about family members opinion about feeding your baby? } \\
\hline Do not care at all, do not care, unsure & $20(22.5)$ & $194(52.4)$ & $77(38.3)$ & $291(44.1)$ \\
\hline Care, care very much & $66(74.1)$ & $168(45.4)$ & $97(48.3)$ & $331(50.1)$ \\
\hline I choose not to answer & $3(3.4)$ & $8(2.2)$ & $27(13.4)$ & $38(5.8)$ \\
\hline Total valid responses & $89(100)$ & $370(100)$ & $201(100)$ & $660(100)$ \\
\hline \multicolumn{5}{|c|}{ How much do you care about your healthcare provider's opinion about feeding your baby? } \\
\hline Do not care at all, do not care or unsure & $0(0.0)$ & $4(1.0)$ & $12(6.0)$ & $16(2.3)$ \\
\hline Care or care very much & $89(100)$ & $393(98.5)$ & $170(84.6)$ & $652(94.6)$ \\
\hline I choose not to answer & $0(0.0)$ & $2(0.5)$ & $19(9.4)$ & $21(3.1)$ \\
\hline Total valid responses & $89(100)$ & $399(100)$ & $201(100)$ & $689(100)$ \\
\hline \multicolumn{5}{|c|}{ How much do your cultural beliefs/practices influence your infant feeding choices? } \\
\hline Not at all, Not much, unsure & $44(49.4)$ & $383(96.2)$ & $70(47.9)$ & $497(78.5)$ \\
\hline Much or very much & $43(48.3)$ & 13 (3.3.) & $60(41.1)$ & $116(18.3)$ \\
\hline I choose not to answer & $2(2.3)$ & $2(0.5)$ & $16(11.0)$ & $20(3.2)$ \\
\hline Total valid responses & 89 (100) & $398(100)$ & $146(100)$ & $633(100)$ \\
\hline
\end{tabular}

$(n=393,96.2 \%)$ felt that the reported the influence of cultural beliefs and practices on their infant feeding practices as "not at all," "not much" or "unsure."

Table 4 provides mean scale scores for the three psychosocial parameters included in the multinomial logistic regression. Mean scores on the Iowa infant feeding attitudes scale were Ottawa (59.1 \pm 7.0 ), Miami $(52.6 \pm 7.0)$ and Port Harcourt $(55.7 \pm 6.9)$ out of a total of 85. Mean functional social support scores were Ottawa $(24.8 \pm 6.6)$, Miami $(21.9 \pm 8.1)$ and Port Harcourt $(20.7 \pm 6.2)$ out of a total of 35 . Mean scores on Cohen's perceived stress scale were Ottawa $(15.2 \pm 6.5)$, Miami $(21.1 \pm 6.9)$ and Port Harcourt $(22.1 \pm 4.2)$ out of a total of 40 .

The result of the multinomial logistic analysis is split in Tables 5 and 6 to show parameter estimates of EFF

Table 4 Psychosocial variables of the Black mothers included in the multinomial logistic model

\begin{tabular}{llllll}
\hline Characteristics & $\begin{array}{l}\text { Ottawa, Canada } \\
\text { (M } \pm \text { SD) }\end{array}$ & $\begin{array}{l}\text { Port Harcourt, Nigeria } \\
\text { (M } \pm \text { SD) }\end{array}$ & Miami-Florida, USA (M \pm SD) & $\begin{array}{l}\text { Overall } \\
\text { (M } \pm \text { SD) }\end{array}$ & $\begin{array}{l}\text { Maximum score } \\
\text { attainable }\end{array}$ \\
\hline lowa infant feeding attitude score & $59.1 \pm 7.0$ & $55.72 \pm 6.1$ & $52.6 \pm 6.9$ & $55.2 \pm 6.9$ & 85 \\
Functional social support score & $24.8 \pm 6.6$ & $20.7 \pm 6.2$ & $21.9 \pm 8.1$ & $21.6 \pm 7.0$ & 35 \\
Cohen's perceived stress score & $15.2 \pm 6.5$ & $21.1 \pm 4.7$ & $21.1 \pm 6.9$ & $20.7 \pm 5.9$ & 40 \\
\hline
\end{tabular}


versus MF and EBF versus MF, respectively. Model in each of the tables is the final step of analysis, containing comprehensive entries of predictor variables, which yielded a statistically significant fitted model $\left(X^{2}=243.3\right.$, $p<0.05)$ with a relatively reduced error estimate $(-2$ $\log$-likelihood $=485.2$ ) and an accuracy of $75.1 \%$. Based on their significant $\left(X^{2}\right)$ estimates, each of the consecutive models ( 1 to 4 ) in Tables 5 and 6 show that each step in the analysis had a significant $(p<0.05)$ contribution to Model 5.

\section{Determinants of EFF relative to MF}

Five variables in Model 5 were statistically significant determinants of EFF relative to MF at $p<0.05$ (Table 5): the national guideline of EFF, the existence of cultural beliefs/traditions about infant feeding in the woman's place of origin, pregnancy related healthcare received while living with HIV, received pregnancy healthcare from a nurse or midwife, and perceived stress.

Firstly, for a Black mother whose national guideline is EFF (1), compared to those whose guideline is EBF while on ART (0), had greater relative risk of choosing EFF over MF, holding all other variables in the model constant. Black mothers living with HIV and residing in
Ottawa or Miami (relative to Port Harcourt) were several times more likely to practice EFF than MF.

Secondly, among mothers who said "yes" to the existence of cultural beliefs and traditions about infant feeding methods in their place of origin versus those who said "no," the relative risk of practicing EFF relative to MF declined by a factor of 0.2 , holding all other variables in the model constant. That is, mothers were less likely to practice EFF and more likely to practice MF if they reported cultural beliefs and practices about methods of feeding their babies in their places of origin. Thirdly, for mothers who received pregnancy related healthcare while living with HIV compared to those who did not, the relative risk of practicing EFF relative to MF increased by a factor of 21.2, holding all other factors in the model constant. Mothers who received healthcare during pregnancy were 21.2 times more likely to practice EFF instead of MF. Furthermore, among Black mothers living with HIV who received healthcare from a nurse or midwife instead of a medical doctor or clinical officer, the relative risk of EFF relative to MF increased by a factor of 3.1. Mothers who received pregnancy healthcare via a nurse or midwife were more likely to practice EFF instead of MF than those who received healthcare from

Table 5 Results of multinomial logistic regression to determine factors of infant feeding practices (EFF versus MF)

\begin{tabular}{|c|c|c|c|c|c|}
\hline Effects & Model 1 & Model 2 & Model 3 & Model 4 & Model 5 \\
\hline National Guideline $(E F F=1, E B F+A R T=0)$ & $13.6^{*}(0.3)$ & $18.3^{*}(0.4)$ & $35.4^{*}(0.6)$ & $76.7^{*}(0.8)$ & $218.2^{*}(0.9)$ \\
\hline Age (Years) & & $1.1^{*}(<0.1)$ & $1.4(<0.1)$ & $1.1(<0.1)$ & $1.1(<0.1)$ \\
\hline Marital Status (Married =1, Otherwise $=0$ ) & & $0.7(0.4)$ & $0.6(0.5)$ & $0.7(0.5)$ & $0.8(0.5)$ \\
\hline Children born after diagnosed HIV Positive (headcount) & & $0.9(0.2)$ & $1.0(0.3)$ & $0.9(0.3)$ & $0.8(0.3)$ \\
\hline Formal education (Years) & & $0.9(0.1)$ & $0.9(0.1)$ & $0.8^{*}(0.1)$ & $0.9(0.1)$ \\
\hline Employment (Salaried/waged =1, otherwise =0) & & $1.2(0.4)$ & $1.0(0.5)$ & $0.9(0.5)$ & $0.8(0.6)$ \\
\hline $\begin{array}{l}\text { Rating of Baby's father's opinion about infant feeding } \\
\text { (Important }=1 \text {, Otherwise }=0 \text { ) }\end{array}$ & & & $0.8(0.5)$ & $0.6(0.5)$ & $0.7(0.5)$ \\
\hline $\begin{array}{l}\text { Concerns about family members' opinion on infant } \\
\text { feeding (cared }=1 \text {, otherwise }=0 \text { ) }\end{array}$ & & & $0.9(0.4)$ & $0.7(0.4)$ & $0.8(0.4)$ \\
\hline $\begin{array}{l}\text { Are there cultural beliefs/ traditions in your place of } \\
\text { origin about methods of feeding your baby? } \\
\left(\text { Yes }=1, \mathrm{No}^{\prime}=0\right)\end{array}$ & & & $0.2^{*}(0.6)$ & $0.2^{*}(0.6)$ & $0.2^{*}(0.7)$ \\
\hline Received health care during pregnancy? (yes $=1$, No =0) & & & & $14.8^{*}(0.9)$ & $21.2^{*}(1.1)$ \\
\hline $\begin{array}{l}\text { Received healthcare from? (Nurse }=1 \text {, Medical } \\
\text { doctor/clinical officer }=0 \text { ) }\end{array}$ & & & & $2.6(1.0)$ & $3.1^{*}(0.5)$ \\
\hline Infant feeding attitude (score on lowa scale) & & & & & $1.1(<0.1)$ \\
\hline Functional Social Support (score on scale) & & & & & $1.04(<0.1)$ \\
\hline Perceived Stress (score on Cohen's scale) & & & & & $0.9^{*}(0.1)$ \\
\hline \multicolumn{6}{|l|}{ Model summary } \\
\hline (-2 Log Likelihood) & 20.2 & 543.0 & 532.5 & 490.5 & 485.2 \\
\hline Chi-square statistics $\left(X^{2}\right)$ & $339.4^{*}$ & $312.3^{*}$ & $231.6^{*}$ & $229.2^{*}$ & $243.3^{*}$ \\
\hline Observations analysed, n (\%) & $373(54.1)$ & & & & \\
\hline Accuracy (\%) & 76.8 & 75.3 & 73.1 & 74.6 & 75.1 \\
\hline
\end{tabular}

${ }^{* * *} p<0.001,{ }^{* *} p<0.01,{ }^{*} p<0.05$ 
Table 6 Results of multinomial logistic regression to determine factors of infant feeding practices (EBF versus MF)

\begin{tabular}{|c|c|c|c|c|c|}
\hline Effects & Model 1 & Model 2 & Model 3 & Model 4 & Model 5 \\
\hline National guideline $(\mathrm{EFF}=1, \mathrm{EBF}+\mathrm{ART}=0)$ & $0.2^{*}(0.4)$ & $0.2^{*}(0.5)$ & $0.3(0.6)$ & $0.5(0.7)$ & $0.7(0.9)$ \\
\hline Age (Years) & & $1.1^{*}(<0.1)$ & $1.04(<0.1)$ & $1.1(<0.1)$ & $1.0(<0.1)$ \\
\hline Marital Status (Married =1, Otherwise $=0$ ) & & $1.2(0.4)$ & $1.1(0.5)$ & $1.2(0.5)$ & $1.4(0.5)$ \\
\hline Children born after diagnosed HIV Positive (headcount) & & $0.6(0.2)$ & $0.7(0.2)$ & $0.7(0.2)$ & $0.7(0.3)$ \\
\hline Formal education (Years) & & $1.0(0.1)$ & $1.0(0.1)$ & $1.0(0.1)$ & $1.0(<0.1)$ \\
\hline Employment (Salaried/waged =1, otherwise =0) & & $2.2(0.4)$ & $1.7(0.4)$ & $1.9(0.5)$ & $2.3(0.5)$ \\
\hline $\begin{array}{l}\text { Rating of Baby's father's opinion about infant feeding } \\
\text { (Important =1, Otherwise =0) }\end{array}$ & & & $0.7(0.4)$ & $0.6(0.5)$ & $0.6(0.5)$ \\
\hline $\begin{array}{l}\text { Concerns about family members' opinion on infant } \\
\text { feeding (cared }=1 \text {, otherwise }=0 \text { ) }\end{array}$ & & & $1.4(0.3)$ & $1.2(0.4)$ & $1.2(0.4)$ \\
\hline $\begin{array}{l}\text { Are there cultural beliefs/ traditions in your place of } \\
\text { origin about methods of feeding your baby? } \\
\left(\text { Yes }=1, N_{0}=0\right)\end{array}$ & & & $0.5(0.5)$ & $0.5(0.6)$ & $0.5(0.6)$ \\
\hline Received health care during pregnancy? (yes $=1, \mathrm{No}=0$ ) & & & & $13.9^{*}(1.2)$ & $20.2^{*}(1.3)$ \\
\hline $\begin{array}{l}\text { Received healthcare from? (Nurse }=1 \text {, Medical } \\
\text { doctor/clinical officer }=0 \text { ) }\end{array}$ & & & & $1.9(1.2)$ & $2.3^{*}(0.4)$ \\
\hline Infant feeding attitude (score on lowa scale) & & & & & $1.1^{*}(<0.1)$ \\
\hline Functional Social Support (score on scale) & & & & & $1.1^{*}(<0.1)$ \\
\hline Perceived Stress (score on Cohen's scale) & & & & & $0.9^{*}(<0.1)$ \\
\hline \multicolumn{6}{|l|}{ Model summary } \\
\hline (-2 Log Likelihood) & 20.2 & 543.0 & 532.5 & 490.5 & 485.2 \\
\hline Chi-square statistics $\left(X^{2}\right)$ & $339.4^{*}$ & $312.3^{*}$ & $231.6^{*}$ & $229.2^{*}$ & $243.3^{*}$ \\
\hline Observations analysed, n (\%) & $373(54.1)$ & & & & \\
\hline Accuracy (\%) & 76.8 & 75.3 & 73.1 & 74.6 & 75.1 \\
\hline
\end{tabular}

a medical doctor or clinical officer. Finally, for a unit increase in a mother's perceived stress score, the relative risk of EFF relative to MF was reduced by a factor of 0.9 . Mothers with increased perceived stress were less likely to practice EFF and more likely to practice MF.

\section{Determinants of EBF relative to MF}

Five variables were statistically significant determinants of EBF relative to MF in Model 5 (Table 6): healthcare received during pregnancy, healthcare received from a nurse or midwife, IIFAS, functional social support score, and Cohen's PSS.

First, if a Black mother living with HIV received healthcare during pregnancy, the relative risk for her preferring EBF over MF would be expected to increase by a factor of 20.2, given that other variables in the model were held constant. In a broader view, mothers who received healthcare were more likely to practice EBF instead of MF. Second, for mothers who received the healthcare from a nurse or midwife compared to a medical doctor or clinical officer, the relative risk of EBF relative to MF increased by a factor of 2.3. Third, if a mother increased her IIFAS score by one unit, the relative risk for her choosing EBF over MF would be expected to increase by a factor of 1.1, given that other variables in Model 5 were held constant. Next, if the mother's functional social support score increased by one unit, then the relative risk of her preferring EBF to MF would increase by a factor of 1.1. Lastly, a unit increase in the mother's Cohen's PSS would decrease the relative risk of her preferring EBF to MF by a factor of 0.9. In a general sense, an increase in Cohen's PSS reduced the mother's likelihood of choosing EBF over MF. Conversely, the mothers were more likely to prefer MF to EBF when they presented higher perceived stress scores.

\section{Discussion}

This section discusses the statistically significant determinants of infant feeding practices in the study samples. These include the EFF guideline, cultural beliefs and practices, healthcare system, healthcare personnel, infant feeding attitudes, social support, and perceived stress. Key findings discussed were: a national guideline of EFF associated with an increased likelihood of EFF over MF; cultural beliefs and practices about infant feeding associated with a decreased likelihood of EFF over MF; receiving health care during pregnancy by HIV+ women was 
associated with an increased likelihood of EFF over MF, and increased EBF over MF; receiving the health care through a nurse or a midwife was associated with an increased likelihood of EFF over MF, and increased EBF over MF; infant feeding attitude score was associated with an increased likelihood of EFF over MF, and increased EBF over MF; and finally, functional social support score was associated with an increased likelihood of EFF over MF, and increased EBF over MF.

\section{National guideline}

The national guideline of EFF for mothers living with HIV in Canada and the US was associated with increased likelihood of choosing EFF over MF. One principal reason for this would likely be deference by the mothers in Canada and the US to healthcare professional's advice. This is perhaps because mothers might see the advice of health professionals concerning EFF as being the best practice, aligning with approved national guidelines in Canada and the US. In these national contexts, fear of being incriminated for not adhering to national guidelines may be an important factor for explaining why many women living with HIV in Ottawa and Miami choose EFF over other infant feeding methods. Howbeit, statistics in Table 1 show that a few mothers were not adhering to the guideline in their countries. For example, in Ottawa 9.2\% (MF $=3.4 \%$ and $\mathrm{EBF}=5.8 \%)$ and in Miami $12.5 \%(\mathrm{MF}=7.3 \%$ and $\mathrm{EBF}=$ $5.2 \%)$ were not adhering to EFF. Also, in Port Harcourt, $33.3 \%(\mathrm{MF}=15.2 \%$ and $\mathrm{EFF}=18.1 \%)$ were not adhering to the guideline of EBF. Although many of the mothers have their reasons for their practices, non-adherence to guideline recommendations on infant feeding by mothers living with HIV is a critical factor in MTCT of HIV, including maternal and child health. A clear understanding of the guideline over the cultural and perceived Westernized infant feeding norms may be a vital pathway in addressing HIV spread, maternal, and child health. Many women who newly migrated to Canada perceived formula feeding as the modern, Westernized infant feeding method [39]. This perspective may appear realistic in historical statistics. For example, before 1965, breastfeeding initiation among Canadian mothers was less than 25\% [40]. Only $17 \%$ of mothers in Canada in 2003 and 26\% in 2011/2012 breastfed exclusively for 6 months or more [41]. These statistics imply that most Canadian women were formula feeding their babies. Over 70\% of mothers in Ottawa each year, between 2011 and 2015, reported introducing formula before their infants had reached 6 months of age [41]. EBF in the first 6 months of infant life was as low as $13.6 \%$ among Canadian women, demonstrating their inclination toward formula feeding [42]. This perception can also explain why many Black women living with HIV prefer EFF over
EBF. In the US, although $79 \%$ of mothers-initiated breastfeeding in 2011, only $18.8 \%$ practised EBF up to 6 months, and $26.7 \%$ were breastfeeding at 12 months [43]. The guideline of EFF compared to EBF while on ART increased the relative risk of EFF over MF. The preceding result implied that mothers residing in Canada or the US where the national guideline is EFF were more likely to practice EFF over MF than mothers in Nigeria. In contrast, our analysis showed that (EBF) exclusive breastfeeding relative to mixed feeding (MF) was not significantly determined by the Nigerian national guidelines of exclusive breastfeeding (EBF) while on ART. This may be due to family pressure [44] and prevalent cultural norms of MF, in which water and supplementary foods are administered in addition to breastmilk. The other highly probable alternative for Nigerian women would be EBF, which, in economic terms, would be the most feasible; and, again, for women living with $\mathrm{HIV}$, it is the recommended option for guarding against MTCT when the mother is taking ART and has an undetectable HIV viral load. This is especially feasible when mothers have clearly understood the minimal risks of MTCT under these conditions.

\section{Cultural beliefs and practices}

Descriptive analysis show that $21.5 \%$ of mothers from all sites (Table 2) affirmed that there are cultural beliefs and practices in their places of origin about how to feed their babies. Again $18.3 \%$ of the women perceived that cultural beliefs and practices influenced their infant feeding practices at a rating of "much" or "very much". The inferential analysis (Tables 5 and 6) shows that the beliefs and practices concerning methods of infant feeding in the mothers' cultures of origin decrease the mothers' likelihood of choosing EFF over MF. This finding may be corroborating the perception of the few mothers $(18.3 \%)$ who perceived that their infant feeding practices is much or very much influenced by cultural beliefs and practices. In line with the finding, a traditional norm whereby Black African women experience social pressure to MF has been documented in a systematic review [45]. It is customary in many parts of sub-Saharan Africa for mothers to feed their babies breastmilk, water, tea, porridge, and the like within the babies' first few weeks of life [1, 46, 47]. Other studies in the South-South region of Nigeria, where Port Harcourt is located, have found that mothers experience pressures from family members to follow the traditional rites of giving their babies water, herbs, and teas alongside breastfeeding [48]. MF is a cultural practice - a way of treating colic, dehydration, and gastrointestinal distress $[10,49]$. Where cultural expectations about infant feeding methods are not in line with national implementation of WHO guidelines, Black women face a lot of 
tension in their practices of infant feeding method. Such tension is accentuated by HIV-related stigma. For instance, when they choose formula feeding over breastfeeding in adhering to guidelines, they may experience stigma from their community for not acting in the culturally accepted way of mothering [50, 51]. If they choose to breastfeed, they may also experience stigma for attempting to infect the baby with HIV, particularly where the family or community knows about her HIV status [27, 51, 52]. Although HIV stigma is not a fitting variable in the model used in this paper, it is a very important factor that interacts with the mother's cultural expectations to complicate her practices of infant feeding practices.

\section{Healthcare system}

This study found that mothers who received healthcare during their pregnancies while living with HIV were more likely to practice EFF over MF than were mothers who did not receive such healthcare. Similarly, mothers who received healthcare during their pregnancy while also receiving ART were more likely to chose EBF over MF. This result is corroborated by findings that the health system supports the $\mathrm{WHO} /$ national recommendations on infant feeding practices [45]. Three platforms through which the health system provides infant feeding support include pre-delivery maternal counseling, post-delivery maternal support, and counseling from health workers [22, 53-55]. While healthcare systems can be nurturers or enablers of approved recommendations, the extant literature has shown that healthcare workers can have divergent influences on mothers' infant feeding practices. Healthcare workers are likely to give adapted messages based on what they believed to be the best feeding practices for mothers $[49,56,57]$. For example, some studies have found that EFF has been suggested for women of high socioeconomic status while EBF has been recommended to mothers of low socioeconomic status [58, 59]. In other instances, health workers have been concerned that EBF would be challenging for women they perceived as undernourished, and, in some cases, healthcare workers have not supported sixmonth EBF because they believed the practice was unfeasible for women who would be leaving their infants at home with caregivers when they resumed work in early postpartum [58]. Mixed messaging was reported when women living with HIV were informed that breastfeeding is a mode of MTCT, while EBF is a means of prevention, without a clear explanation about the exact risk of transmission through breastfeeding with and without ART [60].

\section{Healthcare personnel}

Mothers who received pregnancy healthcare from a nurse or midwife instead of a medical doctor or clinical officer were more likely to practice EFF compared to MF. They were also more likely to practice EBF than MF. Although a systematic review found that both trained doctors and nurses drive positive change on breastfeeding [61], some others show that medical doctors, including family physicians, do not receive sufficient training about supporting breastfeeding [62-64]. This, perhaps, represents a need for focused training on the details of infant feeding recommendations, including EFF and EBF for mothers living with HIV. Many physicians do not advocate breastfeeding for fear that it may culminate in parental guilt among some mothers [64], but this is not the case if parents are adequately educated about their practices [65]. While medical doctors provide counseling, nurses have an educational role in breastfeeding advocacy; they are responsible for providing educational supports to women, so mothers can make informed decisions to formula feed and administer the formula in a safe and nurturing way [66].

\section{Mothers' infant feeding attitudes}

This research has found that a unit increase in a mother's IIFAS score predicted her choosing EBF over MF at a statistically significant level. This result is congruent with two past research findings which showed that IIFAS score was associated with infant feeding practices and breastfeeding duration among breastfeeding women $[67,68]$. A study in rural Western Australia found that women with more positive attitudes towards breastfeeding had longer durations of $\operatorname{EBF}[69,70]$. Another study found that women who perceived breastfeeding to be healthier, easier, and more convenient breastfeed longer than those who perceive it to be restrictive, inconvenient and uncomfortable [71]. Thus, attitude towards breastfeeding, as measured by the IIFAS, is a predictor of EBF, as found in this study.

\section{Functional social support}

Functional social support was associated with an increased likelihood of EBF over MF. This may be linked with the fact that functional social support provides emotional, information and material need of the mother to help her fully to adhere to the guideline of EBF. Many mothers without such support may lack information about ART, or not fully understand the reduction in the risk of MTCT of HIV when they are on ART. Mothers residing in many parts of Africa with little access to safe and nutritionally adequate alternatives to breastmilk can only allay fears of MTCT and practice EBF with sufficient functional social support. These levels of social support become a motivation for adhering to ART and 
help them understand the safety of EBF when their viral loads are undetectable. In 2016, WHO recommended being fully supported for ART adherence, for mothers living with HIV in countries where EBF is encouraged [6]. Hence, both ART and EBF can be fostered by functional social support as indicated in our finding. A lifelong ART, including adherence counselling and promotion of EBF and its duration would be key elements of social support system for mothers living with HIV. In line with the present findings, some recent studies have found that EBF is positively influenced by social support [72-74]. Beyond this, a study concludes that providing social support to mothers, as well as to other family members (fathers and grandmothers) would improve infant feeding practices [74]. An earlier study also found that social support and material assistance are associated with a decreased likelihood of EBF cessation among mothers living with HIV in Dares Salaam, Tanzania [75].

\section{Perceived stress}

Increased perceived stress has statistically significant, negative effects on both EFF relative to MF, and EBF relative to MF. Although direct, comparable research findings are sparse, several studies, to some degree, support this result. Another study found an association between parenting stress and a composite measure of caretaking difficulties, including infant feeding [76]. Similarly, it has been inferred that high levels of stress are associated with negative parenting practices [77], which would include infant feeding practices. Similarly, maternal stress has been negatively associated with a broad range of parenting skills, which would, again, include feeding practices [78]. A study linked lack of association between MF and perceived stress to insufficient variabilities in the outcome variables (breastfeeding initiation and duration) [79].

Many researchers have often analyzed the relationship between depression (an outcome of stress) and arrays of maternal parenting attributes (including infant feeding practices). The results of such analyses implicitly capture the effects of stress on maternal practices. A study has established that depressive symptoms early in the postpartum period may lower breastfeeding prevalence [80]. In a systematic review, it was inferred that mothers suffering from depression are less likely to initiate breastfeeding; if they do, it will be with decreased duration, and EBF will be less likely [81]. Based on a literature review, it was noted that negative outcomes for infants are due to maternal depression and disorganized infant feeding practices [82], which result in overfeeding or undernutrition [34, 83, 84]. Another recent study has found that postpartum anxiety increases breastfeeding difficulties and may negatively affect breastfeeding behaviors [85].

\section{Limitation}

One limitation of the study was the difficulty we encountered to reach Black mothers living with HIV. This impacted on the study samples sizes, especially in Ottawa. Hence, participants were recruited through venue-based approach at times and places where they would normally convene as opposed to probability sampling. Although this may have limited the generalisation of our results, this approach has been developed, refined, and successfully used in several studies done by members of our research networks. Venue-based approach is an adaptation of the standard approach used in HIV research and provides knowledge of places or groups to target for interventions. To reduce the likelihood of bias in the venue-based sampling, recruitment was strategically spread to as many venues and meetings as possible.

Strength The study provides an understanding of the roles of national guideline, professional advice from healthcare system, and social support in shaping the infant feeding practices of Black mothers living with HIV. It also, paints a clear picture of how cultural values that contradict the infant feeding guideline, and maternal stress can alter infant feeding practices. The paper also draws it strength from the diverse views of Black mothers of various backgrounds including North American born Black mothers, immigrant Black African mothers, and mothers still in their origin in Africa.

\section{Conclusions}

Although the women in our study indicated that cultural expectations were a significant source of stress, the national guidelines on how to feed their infant and health providers advice had more significant impact on their decisions about infant feeding practices among mothers in Canada and US. The providers advice was congruent with WHO and national guidelines for infant feeding among mothers living, which is exclusive formula feeding (EFF). Some mothers in these two North American sites preferred to use mixed feeding, which was against the $\mathrm{WHO} /$ national policy recommendations, but they did not succumb to the pressures of cultural expectations from peers, family, and community members. Mothers from the Nigerian site, who were already taking ART, were also more compliant with the healthcare system advice of EBF over MF. It was interesting to see the influence of health care providers on these mothers' infant feeding practices in all three sites: Canada, the US and Nigeria. This is especially so if the mothers have received healthcare through a nurse practitioner and have 
social support from friends and families. This speaks to the need for health care providers to have updated knowledge of advances in HIV prevention and care cascade. Women dealt with stress with other strategies such as hypervigilance, use of mixed methods feeding, etc.

These results point to the importance of health care providers providing evidence-based HIV prevention and care. Educational programs for health care providers such as nurses and midwives need to have HIV care as a core aspect of curriculum content. In addition, health care providers need to be practice in culturally safe and responsive manner to meet the needs of Black women who are living with HIV. Global and national guidelines also need to take into consideration the unique needs of those that are impacted by such policies. For example, Black women living with HIV should be meaningfully engaged with other stakeholders at the arenas where the WHO and national guidelines are developed to ensure better alignment with their socio-cultural contexts. Respective national governments are to provide continued training programs for healthcare workers concerning the rationale for the infant feeding policy recommendations and should educate medical doctors and clinicians to develop social support skills so that they may further teach mothers. Finally, given that some mothers especially those that have been historically excluded from decision making arenas (i.e. Black mothers) may not have the confidence to assert themselves in terms of seeking information to inform health care decisions, it is important to include family members in educational program. Public health education must actively engage families and communities in enlightenment campaigns and community workshops about appropriate infant feeding practices for mothers living with HIV. This will help to them to understand their roles in providing social support to mothers and reduce the pressure to meet cultural expectations of motherhood. It may also help reduce the stigma associated with not breastfeeding. This education will help community members to understand that there are many other reasons outside HIV that could prevent a mother from breastfeeding. Healthcare providers and workers are well-positioned to educate other community and social service providers who will, in turn, educate mothers and their social networks on infant feeding recommendations. Routine visits to healthcare centers for counseling about infant feeding and medication adherence should be undertaken by the mothers themselves, in line with the advice of healthcare workers.

\section{Abbreviations}

HIV: Human Immunodeficiency Virus; ART: Antiretroviral Therapy;

EFF: Exclusive formula feeding; EBF: Exclusive breastfeeding while on ART and viral load monitoring: MF: Mixed feeding; RR: Relative risk: WHO: World Health Organisations, Statistical Package for Social Sciences; MTCT: Mother to
Child transmission; US: United States of America; ACB: African, Caribbean, and Black; AIDS: Acquired Immunodeficiency Syndrome; IIFAS: Iowa Infant Feeding Attitudes Scale; PSS: Perceived Stress Scale

\section{Acknowledgements}

We are grateful to the Black mothers living with HIV who shared their lived experiences and perspectives about their infant feeding practices. We are also grateful to the research assistants, staff, and community stakeholders who helped make this study possible.

\section{Authors' contributions}

Conceptualization, JE.; methodology, JE JH, EBE, SB and JCP; software, EBE, JH and JCP; validation, EBE, SB and JCP; formal analysis, EBE and JCP.;

investigation, JE. JH, SB and JCP; resources, JE.; data curation, EBE, JCP and JE.; writing —original draft preparation, EBE., JCP. JB; writing-review and editing, JB, SB, JCP, EBE and J.H. supervision, JE, JH., SB and JCP; project administration, JE JH, SB and JCP; funding acquisition, JE. All authors have read and agreed to the published version of the manuscript.

\section{Funding}

This study was funded by the Canadian Institutes of Health Research, Institute of Infection and Immunity, Grant \# 144831. The opinions expressed in this manuscript are those of the authors.

Availability of data and materials

Data analysis activities are currently underway. To request access to study data, please contact JE, the principal investigator for the project.

\section{Declarations}

\section{Ethical approval and consent to participate}

The study was approved by the Health Sciences and Science Research Ethics Board at the University of Ottawa (certificate \#H08-16-27), the Carleton University Research Ethics Board-A (CUREB-A, certificate \#106300), the Social and Behavioural Institutional Review Board at Florida International University (certificate \#105160), and the Research Ethics Committee at the University of Port Harcourt (certificate \#UPH/CEREMAD/REC/04). Additionally, permission was obtained from each of the community partner sites where participants were recruited. Informed oral consent was obtained from all individual participants included in the study. The participants preferred oral over written consents because of anonymity having identified as mothers living with HIV. Also, oral consent was most feasible because many of them completed the survey orally with assistant of the survey administrators. The participants consent procedure was approved by the respective ethic boards.

Consent for publication

Not Applicable.

\section{Competing interests}

The authors declare that they have no competing interests.

\section{Author details}

${ }^{1}$ School of Nursing, Faculty of Health Sciences, University of Ottawa, 451 Smyth Road, Ottawa, Ontario K1H 8M5, Canada. ${ }^{2}$ Nicole Wertheim College of Nursing and Health Sciences, Florida International University, 11200 Southwest 8th Street, Miami, FL 33199, USA. ${ }^{3}$ Department of Sociology, Anthropology \& Criminology; Faculty of Arts, Humanities \& Social Sciences, 401 Sunset Avenue, Windsor, Ontario N9B 3P4, Canada. ${ }^{4}$ Centre for Health and Development, University of Port Harcourt, Port Harcourt, Nigeria.

Received: 1 April 2020 Accepted: 22 March 2021

Published online: 07 April 2021

References

1. Fadnes LT, Engebretsen IMS, Moland KM, Nankunda J, Tumwine JK, Tylleskär T. Infant feeding counselling in Uganda in a changing environment with focus on the general population and HIV-positive mothers - a mixed method approach. BMC Health Serv Res. 2010;10(1):260. https://doi.org/1 0.1186/1472-6963-10-260.

2. Avert: Global Information and Education on HIV and AIDS. Prevention of mother-to child transmission (PMTCT) of HIV. https://www.avert.org/ 
professionals/hiv-programming/prevention/prevention-mother-child. Accessed 15 Oct 2015

3. Greene S, Ion A, Elston D, Kwaramba G, Smith S, Carvalhal A, et al. "Why Aren't you breastfeeding?": how mothers living with HIV talk about infant feeding in a "breast is best". World Health Care Women Int. 2015;36(8):883901. https://doi.org/10.1080/07399332.2014.888720.

4. UNAIDS. United Nations Joint Programme on HIV/AIDS (UNAIDS) and WHO 2012. 2012. https://www.unaids.org/en/resources/documents/2012/2012112 0_UNAIDS_Global_Report_2012. Accessed 15 Oct 2015.

5. WHO. Guidelines on HIV and infant feeding: principles and recommendations for infant feeding in the context of HIV and a summary of evidence. 2010. http://apps.who.int/iris/bitstream/10665/44345/1/9789241 599535_eng.pdf. Accessed 1 Feb 2019.

6. WHO. Guideline updates on HIV and infant feeding: the duration of breastfeeding and support from health services to improve feeding practices among mothers living with HIV. 2016. https://www.who.int/ma ternal child adolescent/documents/hiv-infant-feeding-2016/en/

7. Loutfy MR, Margolese S, Money DM, Gysler M, Hamilton S, Yudin MH. Canadian HIV pregnancy planning guidelines. J Obstet Gynaecol Can JOGC. 2012;34(6):575-90. https://doi.org/10.1016/S1701-2163(16)35274-4.

8. Ekanem $\mathrm{EE}$, Gbadegesin A. Voluntary counselling and testing $(\mathrm{VCT})$ for human immunodeficiency virus: a study on acceptability by Nigerian women attending antenatal clinics. Afr J Reprod Health. 2004;8(2):91-100. https://doi.org/10.2307/3583183.

9. Agunbiade OM, Ogunleye OV. Constraints to exclusive breastfeeding practice among breastfeeding mothers in Southwest Nigeria: implications for scaling up. Int Breastfeed J. 2012;7(1):5. https://doi.org/10.1186/1746-43 58-7-5.

10. Østergaard LR, Bula A. "they call our children "Nevirapine babies?" ": a qualitative study about exclusive breastfeeding among HIV positive mothers in Malawi. Afr J Reprod Health. 2010;14(3):213-22.

11. Ahmed A. HIV and women: incongruent policies, criminal consequences SSRN scholarly paper. Rochester: Social Science Research Network; 2011. https://papers.ssrn.com/abstract=1974628. Accessed 21 Feb 2021.

12. Ioannidis JP, Abrams EJ, Ammann A, Bulterys M, Goedert JJ, Gray L, et al. Perinatal transmission of human immunodeficiency virus type 1 by pregnant women with RNA virus loads $<1000$ copies/ml. J Infect Dis. 2001; 183(4):539-45. https://doi.org/10.1086/318530.

13. Buchanan AM, Cunningham CK. Advances and failures in preventing perinatal human immunodeficiency virus infection. Clin Microbiol Rev. 2009; 22(3):493-507. https://doi.org/10.1128/CMR.00054-08.

14. Etowa J, Matthews SV, Vukic A, Jesty C. Uncovering Aboriginal nursing knowledge through community based participatory research (CBPR). Indig Policy J 2011;22. http://www.indigenouspolicy.org/index.php/ipj/article/ view/3. Accessed 21 Feb 2021.

15. Airhihenbuwa C, Okoror T, Shefer T, Brown D, Iwelunmor J, Smith E, et al. Stigma, culture, and HIV and AIDS in the Western cape, South Africa: an application of the PEN-3 cultural model for community-based research. J Black Psychol. 2009;35(4):407-32. https://doi.org/10.1177/0095798408329941.

16. Cowdery J, Parker S, Thompson A. Application of the PEN-3 model in a diabetes prevention intervention. J Health Disparities Res Pract. 2010;4:2641. https://digitalscholarship.unlv.edu/jhdrp/vol4/iss1/3.

17. Scarinci IC, Bandura L, Hidalgo B, Cherrington A. Development of a theorybased (PEN-3 and health belief model), culturally relevant intervention on cervical cancer prevention among Latina immigrants using intervention mapping. Health Promot Pract. 2012;13(1):29-40. https://doi.org/10.1177/1 524839910366416

18. Etowa J, Babatunde S, Hannan J, Etowa EB, Mkandawire P, Loemba H, et al. Motherhood among Black women living with HIV: A "north-south" comparison of sociocultural and psychological factors. Health Care Women Int. 2021:1-19. https://doi.org/10.1080/07399332.2020.1867858

19. Gordon, S. What should we feed baby? Infant formula timeline: The history of baby formula. 2020. http://www.parentschoiceformula.com/articles/Infa nt-Formula-Timeline-What-Should-we-Feed-Baby. Accessed 24 Sep 2020

20. King J, Ashworth A. Historical review of the changing pattern of infant feeding in developing countries: the case of Malaysia, the Caribbean, Nigeria and Zaire. Soc Sci Med. 1987;25(12):1307-20. https://doi.org/10.1016/ 0277-9536(87)90129-8.

21. Pak-Gorstein S, Haq A, Graham EA. Cultural influences on infant feeding practices. Pediatr Rev. 2009;30(3):e11-21. https://doi.org/10.1 542/pir.30-3-e11.
22. Kapiriri L, Tharao WE, Muchenje M, Masinde KI, Siegel S, Ongoiba F. The experiences of making infant feeding choices by African, Caribbean and black HIV-positive mothers in Ontario, Canada. World Health Popul. 2014; 15(2):14-22. https://doi.org/10.12927/whp.2014.23860.

23. Magwaza T. Perceptions and experiences of motherhood: a study of black and white mothers of Durban, South Africa. JENdA J Cult Afr Women Stud 2003;0:1-14. https://www.africaknowledgeproject.org/index.php/jenda/a rticle/view/84. Accessed 22 Feb 2021.

24. Khosla P, Ion A, Greene S. Supporting mothers in ways that work: a resource toolkit for service providers working with mothers living with HIV. Hamilton: The HIV Mothering Study Team and the Ontario Women's HIV/AIDS Initiative; 2016. https://www.actioncanadashr.org/sites/default/files/2019-04/ SMWTW_FINAL_Jan2016.pdf

25. Tuthill EL, Tomori C, Van Natta M, Coleman JS. "In the United States, we say, 'No breastfeeding,' but that is no longer realistic": provider perspectives towards infant feeding among women living with HIV in the United States. J Int AIDS Soc. 2019;22(1):e25224. https://doi.org/10.1002/jia2.25224.

26. Etowa, J., Hannan, J., Babatunde, S., Phillips, J. C., Loemba, H., Mildred, J., et al. Infant feeding among black women living with HIV: a community based participatory research. 2016.

27. Oladokun RE, Brown BJ, Osinusi K. Infant-feeding pattern of HIV-positive women in a prevention of mother-to-child transmission (PMTCT) programme. AIDS Care. 2010;22(9):1108-14. https://doi.org/10.1080/0954012 0903511008.

28. QualtricsXM. Provo: Qualtrics; 2019.

29. Phillips JC, Etowa J, Hannan J, Etowa EB, Babatunde S. Infant feeding guideline awareness among mothers living with HIV in North America and Nigeria. Int Breastfeed J. 2020;15(1):27. https://doi.org/10.1186/s13006-020-00274-z.

30. Broadhead WE, Gehlbach SH, de Gruy FV, Kaplan BH. The Duke-UNC functional social support questionnaire. Measurement of social support in family medicine patients. Med Care. 1988;26(7):709-23. https://doi.org/10.1 097/00005650-198807000-00006.

31. de la Mora A, Russell DW, Dungy Cl, Losch M, Dusdieker L. The lowa infant feeding attitude scale: analysis of reliability and Validity1. J Appl Soc Psychol. 1999;29(11):2362-80. https://doi.org/10.1111/j.1559-1816.1999. tb00115.x.

32. Cohen, S. Perceived stress scale. 1994. http://mindgarden.com/documents/ PerceivedStressScale.pdf. Accessed 9 Feb 2018.

33. Cohen S, Kamarck T, Mermelstein R. A global measure of perceived stress. J Health Soc Behav. 1983;24(4):385-96. https://doi.org/10.2307/2136404.

34. Séjourné N, Vaslot V, Beaumé M, Goutaudier N, Chabrol H. The impact of paternity leave and paternal involvement in child care on maternal postpartum depression. J Reprod Infant Psychol. 2012;30(2):135-44. https:// doi.org/10.1080/02646838.2012.693155.

35. Kaufman KJ, Hall LA. Influences of the social network on choice and duration of breast-feeding in mothers of preterm infants. Res Nurs Health. 1989:12(3):149-59. https://doi.org/10.1002/nur.4770120305.

36. Onah S, Osuorah DIC, Ebenebe J, Ezechukwu C, Ekwochi U, Ndukwu I. Infant feeding practices and maternal socio-demographic factors that influence practice of exclusive breastfeeding among mothers in Nnewi south-East Nigeria: a cross-sectional and analytical study. Int Breastfeed J. 2014;9(1):6. https://doi.org/10.1186/1746-4358-9-6.

37. Etowa J, Etowa E, Nare H, Mbagwu I, Hannan J. Social determinants of breastfeeding preferences among black mothers living with HIV in two north American cities. Int J Environ Res Public Health. 2020;17(18). https:// doi.org/10.3390/ijerph17186893.

38. Meshram II, Mallikharjun Rao K, Balakrishna N, Harikumar R, Arlappa N, Sreeramakrishna K, et al. Infant and young child feeding practices, sociodemographic factors and their association with nutritional status of children aged <3 years in India: findings of the National Nutrition Monitoring Bureau survey, 2011-2012. Public Health Nutr. 2019;22(1):104-14. https://doi.org/10.1017/S136898001800294X.

39. DaCosta, S. Ethno-cultural factors influencing infant feeding among south Asians in the region of peel: findings from stakeholder consultations. Brampton and Mississauga: Region of Peel; 2012. http://www.peelregion.ca/ health/library. Accessed 10 Jan 2020.

40. 21. PHA of C (PHAC). Family-centred maternity and newborn care: national guidelines. 2018. https://www.canada.ca/en/public-health/services/ma ternity-newborn-care-guidelines.html. Accessed 6 Jan 2019.

41. Gionet, L. Breastfeeding trends in Canada. 2015. https://www150.statcan.gc. ca/n1/pub/82-624-x/2013001/article/11879-eng.htm. 
42. Al-Sahab B, Lanes A, Feldman M, Tamim H. Prevalence and predictors of 6 month exclusive breastfeeding among Canadian women: a national survey. BMC Pediatr. 2010;10(1):20. https://doi.org/10.1186/1471-2431-10-20.

43. 24. USD of $\mathrm{H}$ and HS. The Surgeon General's call to action to support breastfeeding. 2011. http://www.surgeongeneral.gov/library/calls/brea stfeeding/calltoactiontosupportbreastfeeding.pdf.

44. Maru S, Datong P, Selleng D, Mang E, Inyang B, Ajene A, et al. Social determinants of mixed feeding behavior among HIV-infected mothers in Jos, Nigeria. AIDS Care. 2009;21(9):1114-23. https://doi.org/10.1080/0954012 0802705842 .

45. Etowa J, MacDonald S, Hannan J, Phillips JC, Boadu NY, Babatunde S. Sociocultural factors influencing infant-feeding choices among African immigrant women living with HIV: a synthesis of the literature. J Am Assoc Nurse Pract. 2018;30(4):208-35. https://doi.org/10.1097/JXX 0000000000000014

46. Abiona TC, Onayade AA, ljadunola KT, Obiajunwa PO, Aina OI, Thairu LN. Acceptability, feasibility and affordability of infant feeding options for HIVinfected women: a qualitative study in south-West Nigeria. Matern Child Nutr. 2006;2(3):135-44. https://doi.org/10.1111/j.1740-8709.2006.00050.x.

47. Leshabari SC, Blystad A, Moland KM. Difficult choices: infant feeding experiences of HIV-positive mothers in northern Tanzania. SAHARA J J Soc Asp HIVAIDS Res Alliance. 2007;4:544-55.

48. Onono MA, Cohen CR, Jerop M, Bukusi EA, Turan JM. HIV serostatus and disclosure: implications for infant feeding practice in rural South Nyanza, Kenya. BMC Public Health. 2014;14(1):390. https://doi.org/10.1186/1471-24 58-14-390.

49. Sphiwe M, Jonas L. Cultural practices interfere with adherence to exclusive infant feeding : a qualitative study among HIV positive post natal women in Hammanskraal, South Africa : child nutrition and feeding practices. Afr J Phys Health Educ Recreat Dance. 2014;20(sup-1):264-78.

50. Mahajan AP, Sayles JN, Patel VA, Remien RH, Sawires SR, Ortiz DJ, et al. Stigma in the HIV/AIDS epidemic: a review of the literature and recommendations for the way forward. AIDS. 2008;22(Suppl 2):S67-79. https://doi.org/10.1097/01.aids.0000327438.13291.62.

51. Etowa J, Hannan J, Babatunde S, Etowa EB, Mkandawire P, Phillips JC. HIVrelated stigma among black mothers in two north American and one African cities. J Racial Ethn Health Disparities. 2020;7(6):1130-9. https://doi. org/10.1007/s40615-020-00736-4.

52. Tariq S, Elford J, Tookey P, Anderson J, de Ruiter A, O'Connell R, et al. "It pains me because as a woman you have to breastfeed your baby": decision-making about infant feeding among African women living with HIV in the UK. Sex Transm Infect. 2016;92(5):331-6. https://doi.org/10.1136/ sextrans-2015-052224.

53. Adejuyigbe E, Orji E, Onayade A, Makinde N, Anyabolu H. Infant feeding intentions and practices of HIV-positive mothers in southwestern Nigeria. Hum Lact Off J Int Lact Consult Assoc. 2008;24:303-10.

54. Ndubuka J, Ndubuka N, Li Y, Marshall CM, Ehiri J. Knowledge, attitudes and practices regarding infant feeding among HIV-infected pregnan women in Gaborone, Botswana: a cross-sectional survey. BMJ Open. 2013;3:e003749.

55. Chisenga M, Siame J, Baisley K, Kasonka L, Filteau S. Determinants of infant feeding choices by Zambian mothers: a mixed quantitative and qualitative study. Matern Child Nutr. 2011;7(2):148-59. https://doi.org/10.1111/j.17408709.2010.00264.x

56. Tijou Traoré A, Querre M, Brou H, Leroy V, Desclaux A, Desgrées-du-Loû A. Couples, PMTCT programs and infant feeding decision-making in Ivory Coast. Soc Sci Med. 2009;69(6):830-7. https://doi.org/10.1016/.jsocscimed.2009.06.001.

57. Wachira J, Otieno-Nyunya B, Ballidawa J, Braitstein P. Assessment of knowledge, attitudes and practices of infant feeding in the context of HIV: a case study from western Kenya. SAHARA J J Soc Asp HIVAIDS Res Alliance. 2009:6:120-6 quiz 127-33.

58. Chinkonde JR, Hem MH, Sundby J. HIV and infant feeding in Malawi: public health simplicity in complex social and cultural contexts. BMC Public Health. 2012;12:700

59. Koricho AT, Moland KM, Blystad A. Poisonous milk and sinful mothers: the changing meaning of breastfeeding in the wake of the HIV epidemic in Addis Ababa, Ethiopia. Int Breastfeed J. 2010;5(1):12. https://doi.org/10.11 86/1746-4358-5-12

60. Laar SA, Govender V. Factors influencing the choices of infant feeding of HIVpositive mothers in southern Ghana: the role of counsellors, mothers, families and socio-economic status. J AIDS HIV Res. 2011;3:129-37.
61. McFadden A, Gavine A, Renfrew MJ, Wade A, Buchanan P, Taylor JL, et al. Support for healthy breastfeeding mothers with healthy term babies. Cochrane Database Syst Rev. 2017. https://doi.org/10.1002/14651858. CD001141.pub5.

62. Mottl-Santiago J, Walker C, Ewan J, Vragovic O, Winder S, Stubblefield P. A hospital-based doula program and childbirth outcomes in an urban, multicultural setting. Matern Child Health J. 2008;12(3):372-7. https://doi. org/10.1007/s10995-007-0245-9.

63. Newton KN, Chaudhuri J, Grossman X, Merewood A. Factors associated with exclusive breastfeeding among Latina women giving birth at an inner-city baby-friendly hospital. J Hum Lact Off J Int Lact Consult Assoc. 2009;25:28-33.

64. Montgomery A, Dermer A, Eglash A, Quiogue M, Saenz RB, Tobolic TJ. Breastfeeding, family physicians supporting (position paper). Am Fam Physician. 2015;9:56-7.

65. Moore ER, Anderson GC, Bergman N, Dowswell T. Early skin-to-skin contact for mothers and their healthy newborn infants. Cochrane Database Syst Rev. 2012;5:CD003519.

66. 46. RNA of O (RNAO). Breastfeeding: fundamental concepts. a self-Learning package. 2012. https://rnao.ca/sites/rnao-ca/files/Breastfeeding_Fundamenta I_Concepts_-_A_Self-Learning_Package_2012.pdf. Accessed 1 Feb 2020.

67. Dungy C, Losch M, Russell D. Maternal attitudes as predictors of infant feeding decisions. J Assoc Acad Minor Phys. 1994:159-64.

68. Scott JA, Binns CW, Graham Kl, Oddy WH. Temporal changes in the determinants of breastfeeding initiation. Birth Berkeley Calif. 2006;33(1):3745. https://doi.org/10.1111/j.0730-7659.2006.00072.x.

69. Cox KN, Giglia RC, Binns CW. The influence of infant feeding attitudes on breastfeeding duration: evidence from a cohort study in rural Western Australia. Int Breastfeed J. 2015;10(1):25. https://doi.org/10.1186/s13006-0150048-3.

70. Dieterich CM, Felice JP, O'Sullivan E, Rasmussen KM. Breastfeeding and health outcomes for the mother-infant dyad. Pediatr Clin N Am. 2013;60(1): 31-48. https://doi.org/10.1016/j.pcl.2012.09.010.

71. Dennis C-L. Breastfeeding initiation and duration: a 1990-2000 literature review. J Obstet Gynecol Neonatal Nurs JOGNN. 2002;31(1):12-32. https:// doi.org/10.1111/j.1552-6909.2002.tb00019.x.

72. Kimani-Murage EW, Wekesah F, Wanjohi M, Kyobutungi C, Ezeh AC, Musoke $\mathrm{RN}$, et al. Factors affecting actualisation of the WHO breastfeeding recommendations in urban poor settings in Kenya. Matern Child Nutr. 2015; 11(3):314-32. https://doi.org/10.1111/mcn.12161.

73. Ickes SB, Wu M, Mandel MP, Roberts AC. Associations between social support, psychological well-being, decision making, empowerment, infant and young child feeding, and nutritional status in Ugandan children ages 0 to 24 months. Matern Child Nutr. 2018;14(1):e12483. https://doi.org/10.1111/ mcn.12483.

74. Mukuria AG, Martin SL, Egondi T, Bingham A, Thuita FM. Role of social support in improving infant feeding practices in Western Kenya: a quasiexperimental study. Glob Health Sci Pract. 2016;4(1):55-72. https://doi.org/1 0.9745/GHSP-D-15-00197.

75. Petraro P, Duggan C, Msamanga G, Peterson KE, Spiegelman D, Fawzi W. Predictors of breastfeeding cessation among HIV-infected women in Dar Es Salaam, Tanzania. Matern Child Nutr. 2011;7(3):273-83. https://doi.org/1 0.1111/j.1740-8709.2009.00236.x.

76. Ostberg M, Hagekull B. A structural modeling approach to the understanding of parenting stress. J Clin Child Psychol. 2000;29(4):615-25. https://doi.org/10.1207/S15374424JCCP2904_13.

77. Everyday stresses and parenting. In: Handbook of Parenting: Practical Issues in Parenting. 2nd ed. Mahaway: Lawrence Erlbaum Associates; 2002. p. 24367. https://scholar.google.com/scholar_lookup?title=Handbook+of+Pa renting:+Vol.+5.+Practical+issues+in+parenting\&author=KA+Crnic\&author= C+Low\&publication_year=2002\&.

78. Murphy DA, Marelich WD, Armistead L, Herbeck DM, Payne DL. Anxiety/ stress among mothers living with HIV: effects on parenting skills and child outcomes. AIDS Care. 2010;22(12):1449-58. https://doi.org/10.1080/0954 0121.2010 .487085

79. Evans, B. Psychosocial stress, race, and social support among breastfeeding mothers in the American south. 2017. https://scholarworks.gsu.edu/anthro_ theses/123. Accessed 14 Jul 2019.

80. Hatton DC, Harrison-Hohner J, Coste S, Dorato V, Curet LB, McCarron DA. Symptoms of postpartum depression and breastfeeding. J Hum Lact Off J Int Lact Consult Assoc. 2005;21:444-9 quiz 450-4. 
81. Dennis C-L, McQueen K. The relationship between infant-feeding outcomes and postpartum depression: a qualitative systematic review. Pediatrics. 2009; 123(4):e736-51. https://doi.org/10.1542/peds.2008-1629.

82. Agbaere, A. M. Maternal depression, infant feeding practices, and weight gain among African American and Hispanic women. 2015. https://pdfs.sema nticscholar.org/c379/82be4fd2c2379ff133e3264f4d6c367c392a.pdf. Accessed 10 Dec 2019.

83. Mason ZS, Briggs RD, Silver EJ. Maternal attachment feelings mediate between maternal reports of depression, infant social-emotional development, and parenting stress. J Reprod Infant Psychol. 2011;29(4):38294. https://doi.org/10.1080/02646838.2011.629994.

84. Rondinelli AJ, Morris MD, Rodwell TC, Moser KS, Paida P, Popper ST, et al. Under- and over-nutrition among refugees in San Diego County, California. J Immigr Minor Health. 2011;13(1):161-8. https://doi.org/10.1007/s10903-01 0-9353-5.

85. Fallon V, Groves R, Halford JCG, Bennett KM, Harrold JA. Postpartum anxiety and infant-feeding outcomes. J Hum Lact Off J Int Lact Consult Assoc. 2016; 32:740-58.

\section{Publisher's Note}

Springer Nature remains neutral with regard to jurisdictional claims in published maps and institutional affiliations.

- fast, convenient online submission

- thorough peer review by experienced researchers in your field

- rapid publication on acceptance

- support for research data, including large and complex data types

- gold Open Access which fosters wider collaboration and increased citations

- maximum visibility for your research: over $100 \mathrm{M}$ website views per year

At $\mathrm{BMC}$, research is always in progress.

Learn more biomedcentral.com/submissions 